\title{
Die Besten
}

Liebe Leserin, lieber Leser,

mit der neuen Plattform für Start-ups und der Ausrichtung des „Fast Forward Start-up Award“ folgt die Messe München auf der Electronica 2016 einem Trend, der derzeit in der Automobilindustrie wichtige neue Impulse gibt. Es bleibt abzuwarten, ob junge kreative Firmengründer in München zu den potenziellen Fahrzeugzulieferern zählen - oder gar zu den Award-Besten auf der weltgrößten Elektronikmesse.

Im Vorfeld des Events lässt sich nur erahnen, welche Innovationen zu den interessantesten gehören werden. Die Themenbereiche, die der „Automotive Congress“ und das „Automotive Forum“ gesetzt haben, deuten auf die am meisten diskutierten Herausforderungen der Branche hin: im automatisierten Fahren, in Safety \& Security sowie in der Konnektivität und Vernetzung.

Einige Innovationen zeichnen sich bereits in der Forschung und der Vorausentwicklung ab. So schnelllebig der Wandel derzeit in der Automobilindustrie auch sein mag, über einen längeren Zeitraum lassen sich Trends ableiten, von denen wegweisend einige Artikel in der ATZelektronik zeugen. Zu den besten Veröffentlichungen des Magazins in den vergangenen zwölf Monaten zählen sechs Artikel, die wir in dieser Sonderausgabe zur Electronica zusammengestellt haben.

Im Titelthema diskutiert IBM die für die Autoindustrie noch vergleichsweise jungen Security-Strategien in zunehmend vernetzten Automobilen, um diese vor Crackerangriffen zu schützen. Einer der Autoren präsentiert auch auf dem Electronica Automotive Congress. Ein weiteres Messe- und Kongressthema widmet sich der Beschreibung von verbesserten Mensch-Maschine-Schnittstellen. Bei diesen werden der Fahrer und seine kognitiven Fähigkeiten noch zu wenig miteinbezogen - ist es doch der Mensch, der die größte Einflussgröße im Übergabeprotokoll vom manuellen zum automatisierten Fahren und zurück darstellt. Ein Forschungsingenieur bei Harman widmet sich dieser Betrachtung - unserer Meinung nach ein Bestof-Artikel in der ATZelektronik.

Jenseits der zuweilen visionären Veröffentlichungen zu Fahrerassistenzsystemen der Zukunft gilt es, in wichtigen Teildisziplinen zu bestehen, zum Beispiel der Validierung von komplexen Steuergeräten in Echtzeit, wie es b-plus in der Auswahl der besten Artikel zeigt.

Innovative Prozesse, die erst Produktinnovationen ermöglichen, vermissen viele Experten. AB Mikroelektronik gibt hingegen ein gutes Beispiel: mit der Entwicklung einer wegweisenden LEDScheinwerfertechnik, die auch auf der Münchner Messe diskutiert wird. Lesen und bewerten Sie diese und weitere Artikel im Kontext zu Ihren Erfahrungen auf der Electronica. Über ein Feedback würde ich mich freuen.

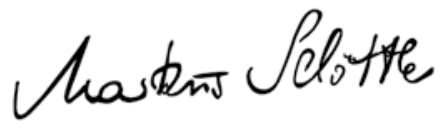

Markus Schöttle

Stellvertretender Chefredakteur

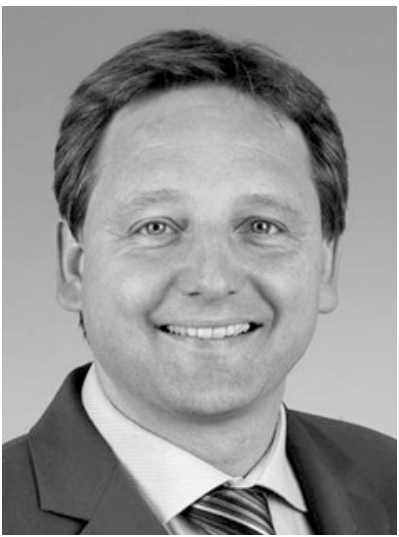

ТГГech

Ensuring Reliable Networks

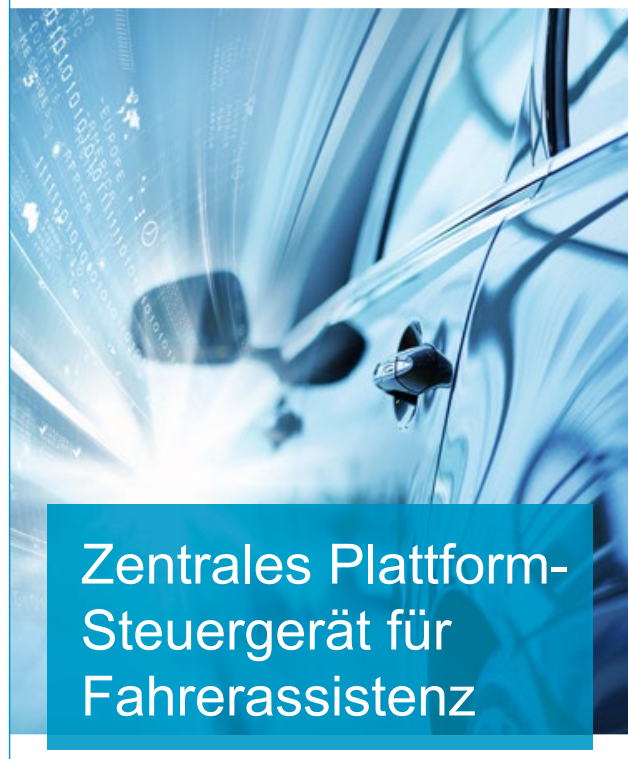

\section{TTA Drive}

- Ethernet-basierte

On-board-Vernetzung

sicherheitsrelevanter

Fahrfunktionen

- Hochintegration verschiedener Assistenzsysteme auf einer Plattform

- Bestmögliche Objekterkennung dank sensorübergreifender Datenfusion

- Skalierbare Architektur

- Zentrale Diagnose aller Systeme

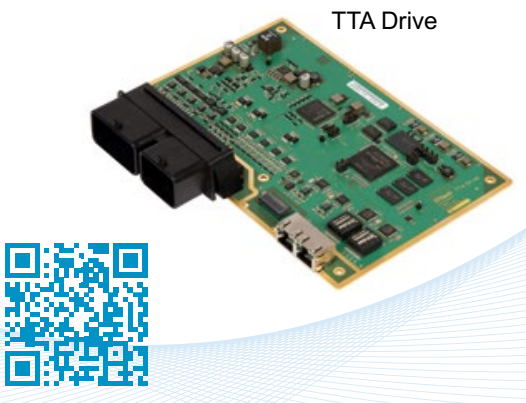

products@tttech-automotive.com

www.tttech.com/ ADAS-TTTech 